\begin{tabular}{|c|c|c|}
\hline AUTHORISI & $\begin{array}{l}\text { C. G. Bathke, CTR-12 } \\
\text { R. A. Krakowski, CTR-12 } \\
\text { R. G. Manzanares, CTR-4 } \\
\text { R. L. Miller, CTR-12 } \\
\text { K. A. Werley, CTR-12 }\end{array}$ & 3007895 \\
\hline
\end{tabular}

Submitien ro International Sympusium on Fusion Nuclear Technology Tokyo Prince Hotel

Tokyo, Japan

IMSI INIFH

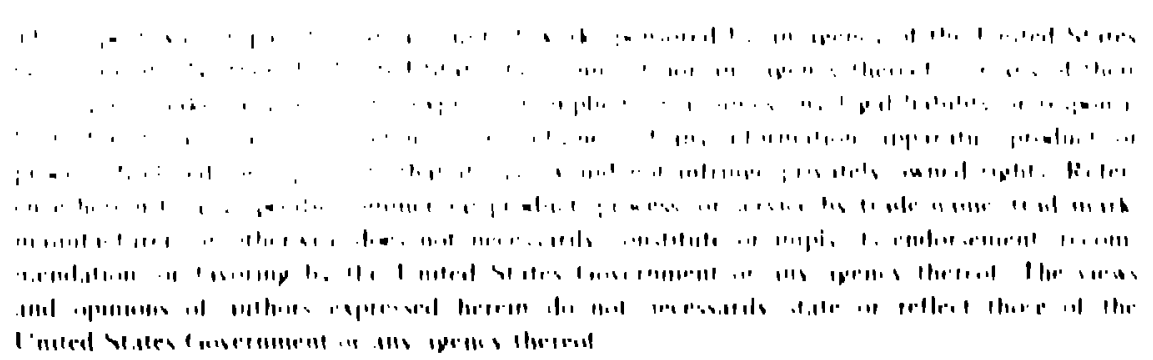

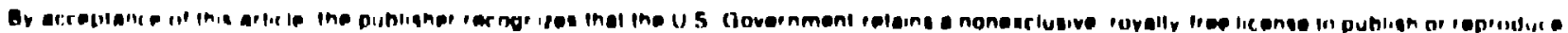

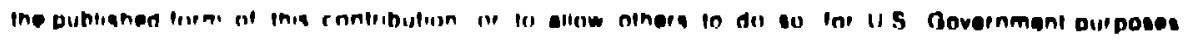

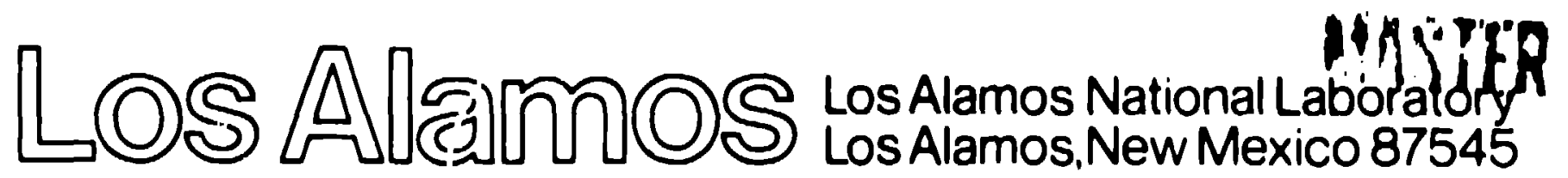




\title{
CONCEPTUAL DESIGN OF A REVERSED-FIELD PINCH FUSION NEUTRON SOURCE*
}

\author{
C. G. Bathke, R. A. Krakowski, R. G. Manzanares, R. L. Miller, and K. A. Werley,
}

Los Alamos National Laboratory, Los Alamos, NM 87545 USA

\begin{abstract}

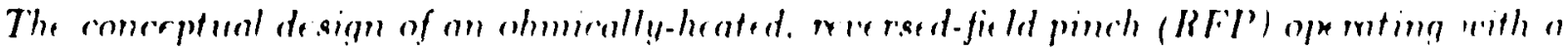

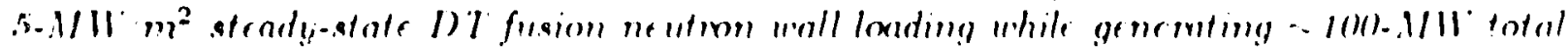

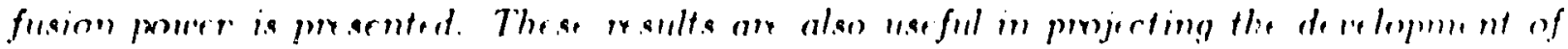

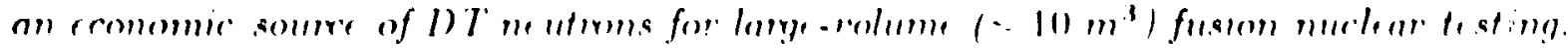

- Work done vinde" auspices of US DOOt 


\section{INTRODUCTION}

A strong experimental database is evolving from a number of relatively snall reversed-field-pincl: (RFP) devices.' Consequently, the design and construction of the next-siep RFPs are well under way in both the US and the European Economic Community. ${ }^{2}$ A recent study of the commercial prospects of the RFP as a high-power-density, compact fusion reactor ${ }^{3}$ has been completed, and a strong economic potential is shouvn should the physics established by existing RFPs extrapolate through the next-step devices to the reactor regime. Preliminary scoping studies of RFPs with characteristics between these next-step devices and the reactor regime recently examined the potential of a RFP ignition burn device as a steady-state source of [)T fusion neutrons".

These results are used to characterize the RFP as a fusion test facility (FTF). This steady-state device would function as a low-to-moderate-Q. driven or margirally ignited FTF with the main goal being the generation of fusion-relevant DT neutron currents $\left(I_{u}: 1-10 \mathrm{MW} / \mathrm{m}^{2}\right)$ from plasmas that are sufficiently small to operate with a total fusion power of $100 \mathrm{MW}$ and without large expenditures in driver power. Central to the viability and or feasibility of this compact approach is the ability to manage heat and particle fluxes in an RFP that differs little in size from the next-step devices:

Tl:e basic approach adopted by this FTF RFP study first dev-loped a quantitative understanding of the available operating space Cost estirnates were also made in the early stages of these analyses to provide guidance Upon selecting a design point from the steady-state parametric analysis.' a two. dimensional viccuum magnetics comput ation st ablished the posision of the equilibrium-field (EF) a"dd ohmic-heating $(\mathrm{OH})$ coils. subject to the usual constraints imposed frvequilibrium and startup (i e plasma breakdown. OH.coil stresses and power) requirements A one-dimensional RFP transport model was used tis estimate radial density and temperature profiles, particularly as determined by the impurity-seeded, high radiation plasma needed to smooth heat fluxes iri ihese compact systems. Buth the detailed coil configuration and plasma profiles ivere then used in the plosma circuit simulatien in deternine the olmically heated startup transient leading to oacillating-field current dive (Or ( $i$ ). and steady state With the basic parameters for the plasma. magnetics (coil sizes, powers. forces) impurity and fueling control, and rurrent drive estat:hshed, ' inclueding all vacuume shielding and conlung

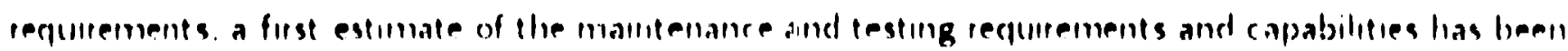
formulated Given below are the esults of each of these subaystem analyses, which coriatine in give a quiantitative mechanical and operational. lefinition of the RFP as a farility for fusion nickear lesting 


\section{RESULTS}

\subsection{Parametric Systems Studies}

Parametric results ${ }^{-4}$ are expressed as contours in a plasma current-radius $\left(I_{t}-r_{p}\right)$ phase space. which is particularly useful in that it measures indirectly two major cost items: (a) coils and power supplies $\left(I_{\phi}\right)$ and $(b)$ the torus $\left(r_{p}\right)$. The parametrics model generates on a plot of $I_{\phi}$ versus $r_{p}$ liiles of constant neutron wall loading, $I_{u}\left(\mathrm{MW} / \mathrm{m}^{2}\right)$, average first-wall heat flux, $q,\left(\mathrm{MW} / \mathrm{m}^{2}\right)$. total fusion power, $\Gamma_{F}(\mathrm{MW})$, constant electron or ion temperature, $T_{1, r}$ (keV), constant electron density, $n_{r}\left(m^{3}\right)$, constant electron streaming parameter, $\xi=n_{n} / l^{\prime} h_{e}$, constant current density, i. $\left(\mathrm{MA} \mathrm{m}^{2}\right)$, constant plasnia loop voltage, $V_{j}(1)$, constant Lawson paraineter, $n \tau_{l:}\left(\mathrm{s} \mathrm{m}^{3}\right)$, and ignition parameter. Selecting the following range for key variables defines the design window used to guide this study: $I_{11} \quad 1-5 \mathrm{MW} \mathrm{m}^{2} . I_{l}, 100 \mathrm{MW}$, and $q .5 \mathrm{MW} / \mathrm{m}^{2}$. Table 1 lists the main parameters for an " $" 0.3-\mathrm{m}$ device operated at $l_{1 "} .5 \mathrm{MW} / \mathrm{m}^{2}$; Reference 4 reports the sensitivity of this design to the main physics parameters listed in Table 1.

\subsection{Magnetics Configuration}

A two-dimensional vacuum magnetics model was used to establish the details of a closely coupled $\mathrm{OH}$ - and EF-coil sets subject to the usua! equilibrium, stress, and power constraints, with the latter two being estimated from a plasma circuit time-dependent simulation. The poloidal-field (PF) coils were nominally positioned a distance from the plasma. Jh. equal to the plasina radius. "., $1 . .$. $m$ Both $\mathrm{OH}$ and toroidal-field (TF) coils are fabricated from aluminun alloy to reduce activation at the expense of 50\% more power consumption Since the EF coils represent the main steady-state power drain, water-cooled copper alloy was selected for the EF-coils Figure 1 gives a torius cross section Routine (i e, daily to monthly) maintenanie and servicing would be thro!igh horiznnt.sl motions outboard of the torus. with the torus divided into relatively independent quadrants separ.at ad by four toroidal-field divertors (Sec 23) Installation and longet :erm mantenance of :he OH arid EF coils would occur by vertical access Coil positions are optimized so that magnefic flux from Ih. back-biased $\mathrm{OH}$.coil is excluded from the plasma chamber to a level that meets maximum veitical field constraints for eflicient plasma breakdown The main PF. coil parameters are listed on Table 11 As seen from rig 1. these constraints are met by a PF.coil set of sufficient outboard openuess to allow horizontal removal of either divertor assemblies or inrus quadrants including the if coils 
The TF coils are aluminum-alloy baras positioned at the minor radius immediately outside the $\Delta \prime^{\prime}=0.3$-m-thick shield test-cell region. The TF coils generally operate at low fields; during the startup phase, most of the toroidal flux within the plasma is provided from the PF-coil set through the RFP dynamo.' The magnitude of the radiai magnetic-field ripple relative to the poloidal field, $\Delta B_{R} / B_{\theta}-0.003$, is chosen to assume acceptably small magnetic islands relative to the distance between the toroidal-field reversal layer and the separatrix. Applying this constraint leads to the TF-coil design summarized in Table III and illustrated on Figs. 1 and 2. The moderate centering and overturning forces on the TF-coils would be supported by a toroidal strong-back that also serves as the outer surface of each blanket quadrant

The divertor-field (DF) coils represent the last major component of the FTF RFP magnetics design. Each of four poloidally-symmetric TF divertors (Sec. 2.3) consists of a single TF nulling coil with flanking coils positio: ed at each side to minimize the perturbation of the reversed toroidal field Table III also gives the main parameters for the DF-coils

\subsection{IMPURITY CONTROL}

Central to the operation of a compact. high-power-density RFP, be it an ignition test device. an FTF, or a cominercial reactor. is the control of high heat and particle fluxes. A number of options: for controlling the particle and energy exhaust was examined," including an armored first-wall. a pump limiter. and a range of magnetic divertors Since the poloidal nagnetic field is 6 minant in the plasma edge. polordally-symmetric limuters and divertors are required to provide magin.tic fielel line connection lengths that are sufficient for radial diffusion of energy and reduced peak heat fluxes Furthermore diversion of the minority (toroidal) field requires less power and minimally perturbs the plasma A closed TF divertor was found to concentrate the heat and particle fluxes to the collector plate The opert divertor configuration shown in Fig 3 avoids this drawback by moving the collector plate closet to the fireld mull. at this point magnetic flux surfaces are exponded and poloidaliy symmetric, as contrasted in the poloidally-asymmetric concentration of field lines that mresents problems for the closed divertor the spen divertor geometiv also allows mon for a latgan collector plate The plate heat flux without plasms iadiation is withen a facton of 3 of the design"

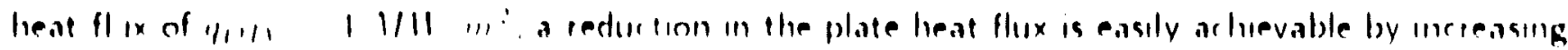
racliation losses by impurity injectinn ( $\left.R, 01^{\circ} \circ X_{n}\right)$

As a result of the sott bets linn: ' observed II RR/F. plasmo parameters and the eneigy confinement are uriaflected by the addition of impunities This behavion is in marked contrast in 
devices not operating at a beta limit in which injecting high- $Z$ impurities increases both the radiation and the total energy loss, and, therefore, degrades energy confinement. The divertor need only remove sufficient impurities so that the impurities in the core plasma can be controlled at the design levels. While an open divertor configuration does not enirain impurities, it must nevertheless physically isolate the hot core plasma from the collector plate to protect both the plasma from neutral atoms and a possibly uncontrolled source of impurities, as weil as protecting the plate from erosion. The minimum separation distance needed to isolate the collector plate from the core plasma is about four neutral-atom ionization mean-free-paths. Typical parameters for the plasma in iront of the collector plate $\left(T, \because T, \sim 10, V^{3}\right.$ and $\left.n, \cdots 10^{21} \mathrm{~m}^{3}\right)$ give a mean-free-path of $0.2 \mathrm{~mm}$. The design shown in rig. 3 locates the plate $15 \mathrm{~mm}$ fro. the core plasma. which is 18 mean-free-paths.

Radial core-plasma. radial edge-plasma, and axial edge-plasma transport calculations for the open divertor give the key parameters for the open-divertor design: peak edge-plasma density and temperatures are $n, 1.2 \cdot 111^{\prime \prime} m, 3,7, \cdots 1111,1$, and $7,2-11,1$. with core-plasma anci total radiation fractions of 0.816 and 0.925 . respectively. The density and temperature near a tungsten. coated divertor plate are about $111^{-1}, 1$ ' and $10=\mathrm{V}$, respectively, which results in negligible erosion: the heat flux normal to the plate is $3 . ; .1 / 11 \mathrm{~m}^{2}$

Plasma density and temperatures near the water-cooled ferritic steel first wall for the divertor corifig:"ration described above are $111^{\prime \prime \prime}, 11$ ' and 1,1 , respectively, with negligible transported heat flux and a radiation heat flux of about $2.1111 \mathrm{~m}^{2}$. Wall erusion by plasma particles is

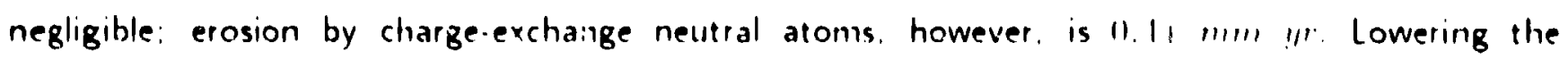
separatrix temperature (e $g$. lower heat flux or higher density), however, has a large effect on the first-wall parameters. A high- $Z$ coating on the first wall would elimnate erosion concerns

A geometry calculation in ronjunction with a hesilflux ce nstiaint determines tlie shape of a divertor plate (Fig 3). Which is located at an a angle relutive in a fielsl line The theemal i.velraulica design was carried out on the inboard side of the divertor plate. where the heat flux is highest anci the space is munimum The heat flux normal to the divertor plate acrounts for transport along field lines. flux-surface expansion. and radiation The flux-surface expansion inclucles the inverse radial dependence of the poloidal field The radiation heat flux is modeled as consisting of iwo parts (a) in radial flux consisting of the core. edge. and half of the divertor tadiated powet. and (b) the othes h.alf of the divertor-padiated power being deposited directly on the collector plate area The simplest divertor plate coolant arrangemeit was selected. which has poloidall; symmetric coolant heaclers 
located external to the divertor nuiling coil (Fig. 3). These headers supply and receive coolant water through copper tubes that $f$,rm the divertor surface. The total coolant path between headers is less than half a meter, and the copper tubes are coated with tungsten to form the collector plate surface. ${ }^{3}$ The collector-plate thermal-hydraulic parameters are given in Table IV.

\subsection{CURRENT DRIVE}

An inductive but oscillatory (i.e., not consumptive of electromagnetic flux) means of steadystate current drive has been proposed for the RFP. Intrinsic plasma processes related to turbulence and or resistive instabilities generate voitage and current within the plasma in order to increase or reduce poloidal flux. so that the masneric flux linkage or helicity is held constant and the plasma resides near a minimum energy state. This nonlinear coupling between plasma and magnetic fields is strong in RFPs and can be used to rectify current oscillations in external coils into a net steady-state current within the plasma. A power balance imposed at the plasma surface, a definition of the plasma internal magnetic energy, and a positive Faraday's Law $(1, n d, ; 1)$ yields an expression for the toroidal voltage around the plasma, 1, , in terms of the poloidal voltage, 1, . and the plasma geometry $\left(r_{r}, R_{r}\right)$. Oscillations of $1 ;$ in proper phase at frequency less than $2 \pi r_{n}$ can give a net timeaveraged current. $I_{0}$, with. $I_{\text {: }} \quad 0$ (1.e. no net flux change), where $T_{H}$ is the instability relaxation time responsible for poloidal-flux generation. Hence, a non-intrusive means to drive current using primarily the main confining coil system to drive low-frequency. low-amplitude plasma oscillations becomes possible.

An assessment of the OFCD engineering efficiency requires the inodeling of the circuit elements external to the plasma to account for all power dissipation. Circuit equations are derived $1:$ for poloidal and toroidal current paths and are labeled (1). . . according in the current direction The circuit elenients simulated are the plasma. first wall. Tf coils, a portion of the OH-coil windings. the blanket, a primary EF-coil set. and a secondary EF coil set Calculations with an electurally continuous first wall indicate a need for resistive breaks or gaps The nindel for circuit elements with electrical gaps is described in Ref 3 or 5

The ORCD results parameterize reactive and dissipative powers as a function of i. "it the operating window of $6 . \ldots$, is bounded above and below because of a loss of field reversal The upper bound is the result of oscillations in . beng to large in anplitude at a sliallow reversal (1) M.11,1 H: 11.1) The lower buund is the esult e' oscillations in 1: iseng to large

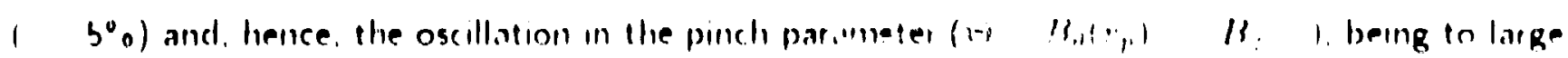


which results in a loss of reversal becaus z adherence to a near-minimum-energy state (e.g. the $I^{\prime}$-(-) curve) is required. The sos, operating window completely disappears below $25 \mathrm{~Hz}$. A summary of typical OFCD parameters is given in Table $\mathrm{V}$.

\subsection{MAINTENANCE AND TESTING GEOMETRY}

\subsubsection{General Layout}

A number of key design choices determine the main features of the FTF, RFP test geonetry. As seen from Fig. 4, the torus is dominated by the PF-coil system, with the TF-coil geometry shown being determined by: (a) field-ripple constraint $\left(\triangle B_{R}^{\prime} B_{R} \quad 0.003\right)$. (b) TF-coil power consumption ( . 10 IMW), and (c) maximized outboard openness for purposes of testing accessibility. The electrically close-coupled PF-coil geometry shown in Fig. 1 was chosen to minimize the capital cost. EF-coil power requirement, and mechanical forces under both operational and fault-mode conditions. Lastly the choice of four divertor sections equally spaced around the torus and the relatively low mass of even the dominant PF-coil set (226-tonne inner $\mathrm{OH}$ coils. 154.3-tonne EF coils plus outer $\mathrm{OH}$ coils) combine with the other constraints to suggest: (a) vertical installation and maintenance of PF. coil sets and the total torus. and (b) horizontal maintenance of individual torus quadrants. divertor subassemblies, and torus-quadrant subassemblies

The horizontal (radial, outboard) maintenance and testing scireme used on the more routine operation requires an outboard access gallery that is sufficiently broad to allow removal and transport of an entire (6.6 tonne) torus quadiant. (first wall. blanket shield, and TF-coils) with divertor assembly (0.8 tonrie) and quadrant blanket shield maintenance servicing being the more frequent operation The need to support both normal (.187 MN) and off-normal (.56 MN no plasma current) EF-coil forces combine with the desire for an outboard toroidal service gallery to require vertical tension compression bars to support the outboard EF.coil forces: these bars would he of nominal $026-11^{2}$ cross section and are located at the outhoard side of each of $N_{11} 28$ TF coils As shown in fig 2. $N_{11} 28$ EF.coil bulkheads of 70 mm theckness and $15 . \mathrm{m}$ radial extent assures EF-coil interspace deflections of less than $1 \mathrm{~mm}$ under operating conditions: the vertical tension compression bars would react the EF-coil forces through each of the correspondung bulklieads This overall arrangement is shown in Fig 3

The choice of both longterm and hort term maintenance schemes and the means to react the EF.coil forces both influence strongly the placement of the vacuum boundary lnitial estimates 
focused on a vacuum chamber into which the entire torus (including all coils) wou!d be placed and in which all short-term (routine) maintenance servicing operations would occur. The need to react these operational loads and to make and break coolant lines under varuum was judged to render less probable the perceived advantages of a large vacuum chamber: eliminating or reducing frequent exposure of the torus to atmospheric pressure and eliminating the complexities related to making vacuum connections directly on the torus. Overly large vacuum chambers wer: also projected if the major operating forces had to be reacted under vacuum. Consequently, a close-fitting vacuum geometry was selected in which all vacuum connections are made primarily at the toroidal shell forming the nuter boundary (i.e.. TF-coil strongback) of each test quadrant and within the TF-coil set. As illustrated in Fig. 2, and in more detail in Fig 3, breakable reweldable seams between divertor sections and torus quadrants would allow removal replacement of each without disturbing the other. Each replaceable divertor assembly would be comprised of divertor plates and associated coolant header manifold, the captive nulling coll, and associated vacuum pump shielding. All TF coils. nulling coils, test-cell quadrants, and first-wall tube banks and associated coolant headering and manifolding together form each of four toroidal quadrants. The cryogenic vacuum pumps, attached to each of four divertor sections would be removed for replacement of either divertor or test quadrants. Similarly, diagnostics and fuel-pellet injectors would have to be disconnected and removed.

2.5.2 Test Arrangement. A given torsidal quadrant test space coula be comprised of a) two "clam-shell" hemi-quadrants, b) single testing spaces fabricated between and under each of the II 2N TF coils. c) or an arrangenent of insertion test rods or "drawers" tailored to support irradiation of multiple specimens or small single effects tests. some of which could be instrumented While the latter approach least interferes with the machine operation, only the outboard portions of the test regions surrounding the plasma would be utilized

Although not available in great detail or for specific tests arrangements at this point in the conceptual FTF RFP design. the preliminary test configuration described above suggests a number of broad testing categories. These categories are summarized below

Plasma-Materials-Interaction (PMI) Tests: These tests would probably be limited to the faw divertor sectors. each giving approximately $1,1, \mid 1,11$ : of area where direct plasma-material interactions could be observed. The overall design anggested above allows for relatively frequent, non interfering horizont al maintenance service of earh divertor section Since the divertor. as well as the first-wall functions directly 
impact overall device operation (e.g., availability), it is likely that tests involving these components will be selected to minimize the impact on the overall machine availability and, therefore. on the bulk radiation tests.

Bulk Radiation Tests: The use of the fusion neutrons can be broadly classified into integrated blanket shield tests performed within a given test quadrant versuls smaller, less-integrated test 5 , a number of which could be conducted in a given quadrant. Each of the fcur quadrants couid in principle be used independently to test fully integrated blanket, shield concepts. The available volume between the first wall and TF-coil array amounts to $8.0 \mathrm{~m}^{3}$ or $0.3 \mathrm{~m}^{3}$ per TFC, with the between undercoil testing volume split being 1:0.5. Hence, it may be possible to dedicate two-

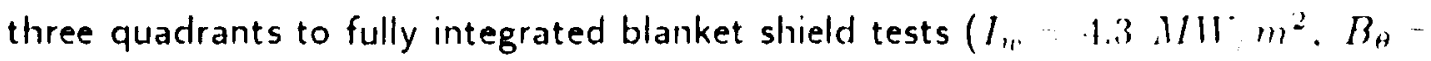

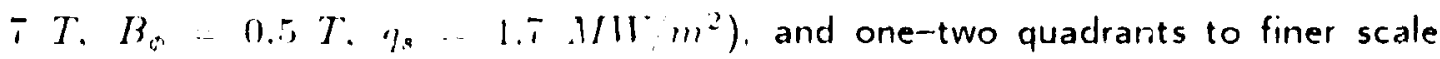
tests ranging from breeder coolant tests of a few per quadrant to single spe-imen nraterials test of one per TF-coil sertor $\left(0.05 \mathrm{~m}^{3}\right.$. highly instrumented interactive) to many per TF coil (high-fluence, multiple specimen, passive). The flexibility in individual TF-coil design (i.e., vertical outboard return leg breakable conductors. etc.) to accommodate $a$ range of active, subsystem tests should be noted.

\section{SUMMARY AND CONCLUSIONS}

The physics required to realize the high-fluence $\left(3.1 .1111 \% l^{\prime}, i^{2}\right.$ per year at $80^{\circ}$ o availability). high-volume $\left(111 \mathrm{~m}^{3}\right)$. low-power (124 MW fusion power, $152 \mathrm{MW}$ input power) ne:stron source will not be available until after the RFPs presently being constructed have operated. The fatabase for this fusion nuclear-testing facility. therefore, would not be available until after the year 1995. Given that high-current RFPs in relatively compact geometry can be demonstrated within this time frame. however, an efficient and cost effective neutron source that is capable of providing a majority of small-sample and integrated test needs for fusion could be available by the year 2000 


\section{REFERENCES}

1. H. A. Bodin, R. A. Krakowski, and S. Ortolani, "The Reversed-Fiald Pinch: from Experiment to Reactor." Fius. Tfe'lmolon!! 10, 307 (1986)

2. D.B. Thomson (ed.). "Proceedings of the International Workshop on Engineering Design of Next Step Reversed Field Pinch Devices", Los Alainos National Laboratory Report LA-11139-C (July 13-17, 1987).

3. The TITAN Research Group, "The TITAN Reversed-Field Pinch Reactor Study-The Final Report," University of California-Los Angeles. GA Technologies, Ine.. Los Alamos National Laboratory, and Rensselaer Polytechnic Institute UCLA-PPG-1200 (to be published 1988)

4. C. G Bathke, R. A Krakowsti, R. L. Miller, and K. A. Werley. "A DT Fusion Neutron Source Based on the Reversed-Field Pinch." Proceedings of 12 th IEEE Symposium on Fusion Engineering. Monterey, CA (October 12-16, 1987).

5. C. G. Bathke. "The Oscillating-Field Current Drive System," Proceedings of 12th IEEE Symposium on Fusion Engineering. Monterey, CA (October 12-16, 1987)

6. K. A. Werley. C. G. Bathke, and R. A. Krakowski, "Edge Plasmas and Plasma Wall Interactions in an Ignition-Class Reversed-Field Pinch." Proceedings of 12th IEEE Symposium on Fusion Engineering. Monterey. CA (October 12-16, 1987). 


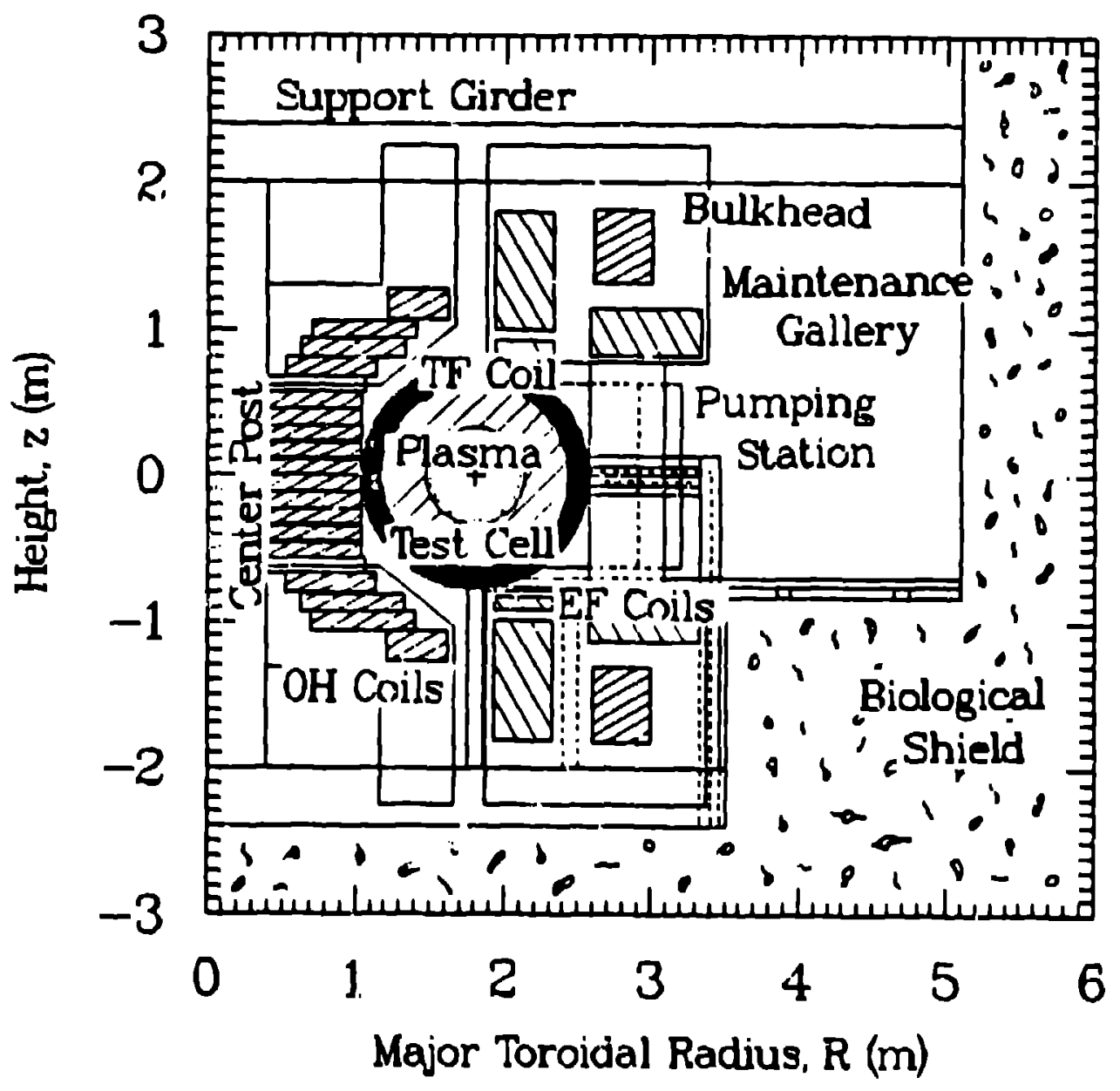

Fiqure 1. Elevation view of OH-.EF-, and TF-coil sets for FTF RFP st:- wing the support structure and hoizontal access to blanket test. regions. 


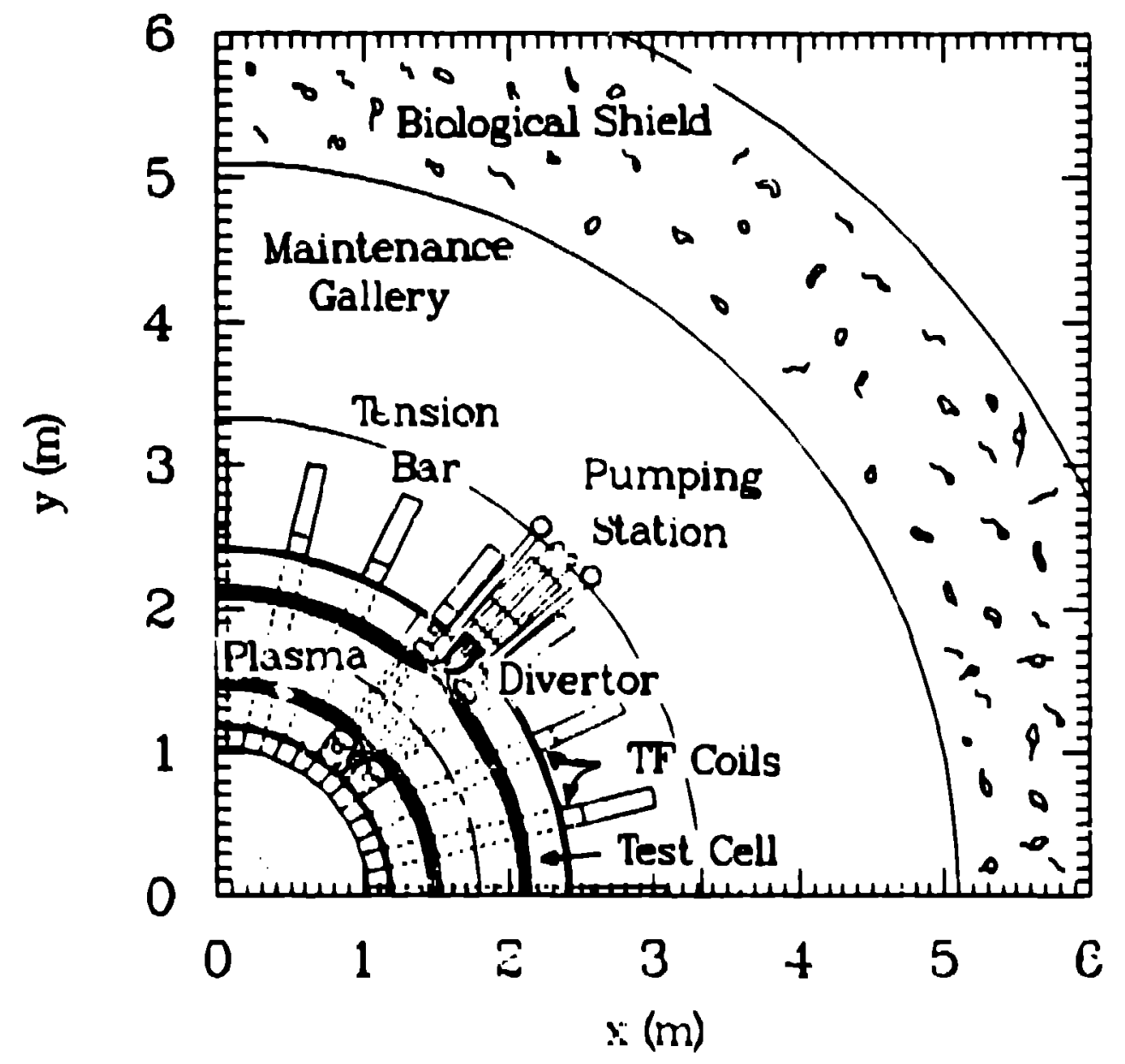

Figure 2. Plan view of FTF RFP torus showing (a) TF coils that meet the $\Delta\left\|_{1:}\right\|_{11} \quad 11$ 1111:3 ripple constraint and. (b) the poloidally symmetric torocdal field divertor, and (c) vacuum boumelary and pumping station. 


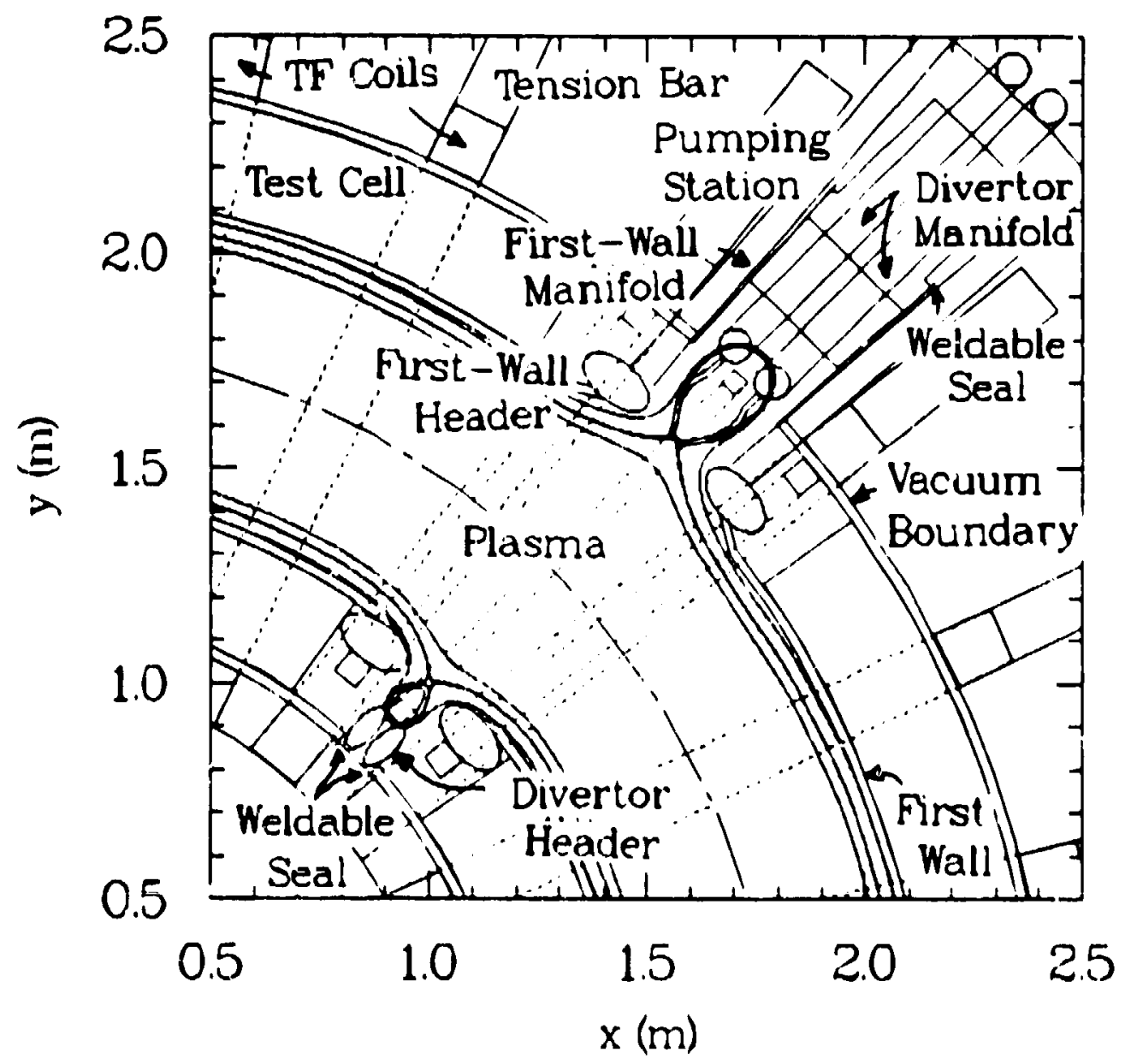

Figure 3. Detailed plan view of divertor ald vacuun comnections 


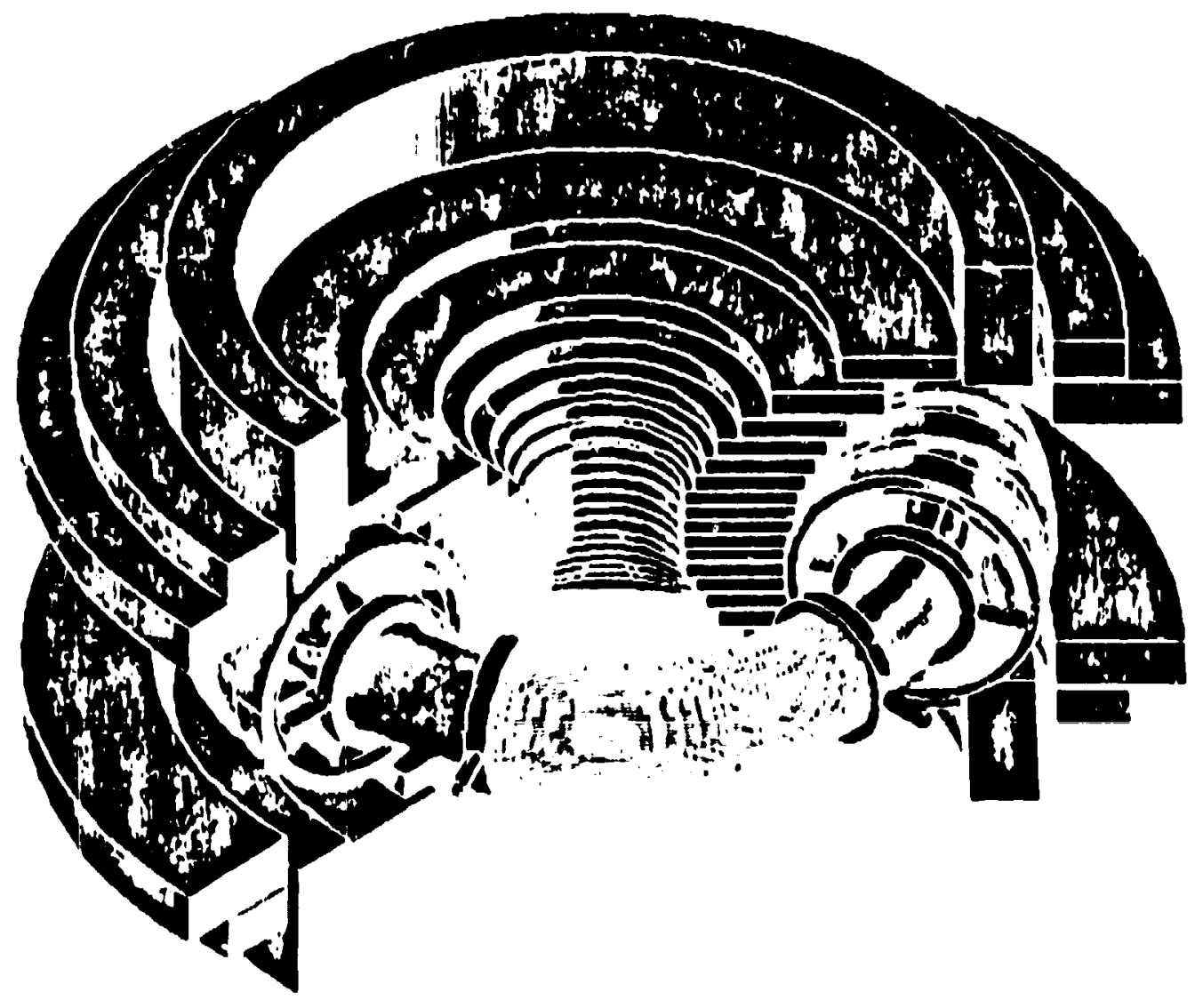

Figure 4. isometric view of FTF RFP Intus and coil pomertiy 
TABLE I. DEVICE PARAMETERS FOR FTF RFP

Parameter

Value

Plasma major radius, $R_{7}(m)$

Plasma minor radius, $r_{p}(m) \quad 0.3$

Plasma aspect ratio, $A-R_{T} / r_{p} \quad 6$.

Flasma shape

Plasma volume, $\operatorname{li}_{r}\left(m^{3}\right)$

circular

First-wall area, $d_{F} \| l\left(m^{2}\right) \quad 23.45^{(1)}$

Blanket shield thickiass, $\Delta /(m)^{(b)} \quad 0.30$

Blanket shield volume, $I_{B I K}\left(\mathrm{~m}^{3}\right) \quad 10.23^{1 \cdot)}$

Pinch pararieter, $\left.(-) \quad B_{H}\left(r_{,}\right): B_{0}\right) \quad 1.52$

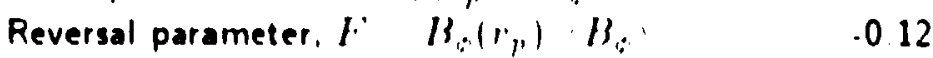

Poloidal field at plasma edge, $H_{N}(T) \quad 6.8$

Toroidal field at plasma edge. $13.1 \%$, $\quad 0.5$ ?

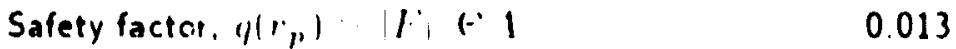

Poloidal beta. $i t_{A} \quad 0.10$

Average electron temperature. $\mathrm{l}, 1 \mathrm{ki}, \mathrm{l}) \quad 900$

Average ion temperature, $l i l l i, 1) \quad 853$

Average electron density, $11,1111^{2 \prime \prime}, 111$, 6.87

Effective piasma alomic number. $\%, \ldots, \quad 16,9$

Toroical plasma current. $1.1 .1 / .11 \quad 1020$

Plasma current density. $1.11 \mathrm{l} .1 \mathrm{~m} 21 \quad 3608$

Lawson parameter, $11 r_{1} 11111^{\prime \prime}: m^{\prime \prime} \quad 078$

Anomalous ohmic heating of ions. $f, 1 / 1^{1 / 1} \quad 0$

Ohmic power in plasma. / $13,1,1 / 11$ 1 247

Fraction of alpha.particle ellergy to plasma. I. 10

Fusion power, $11,1.1 / 111$ 1242

Plasma Q-value (), l'l lin, 503

First-wall hent fllux. $1,1,1 / 11,111,172$

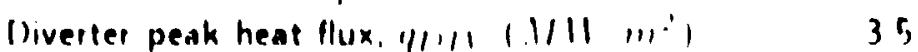

Fusion neution first.wall loading. $1,1.1 / 11{ }_{11}=4$

Masma loop voltage. 1.111 24.

Streaming parameter, \& $1 \%, 1 \%$. 00058

Poloidal flux, I., $I_{\text {, }}(1 \mathrm{ll}$ h) 64.14

Tiansport ocaling parameter, $11 \%$, 1125

(11) Theoletical value. Hivertors reduce first. wall coverage to 0.87 .

(h) Assumed for purposes of subsequent magnetic calculation

(r) Theoretical value. livertors and first. wall coolant headers ceduce blanket coverag to 0.78

(i) Actually observed in RFI' experiments 
TABLE II. PF.COIL PARAMETERS FOR THE FTF RFP

Parameter

Value

Current (MA)

Volume ( $\left.m^{3}\right)$

Mass (tonne)

Joule losses (MW)

Peak field (T)

Current density $\left(\mathrm{MA} / \mathrm{m}^{2}\right)$

EF. Coil vertical field index

OH.Coil stray vertical field $(m T)^{(h)}$

PF. Coil vertical transparency $\left({ }^{\circ},\right)$

\section{OH Coils EF Coils}

$22.57^{(11)}(.34 .03)^{(1)} \quad 11.46^{\prime \prime}$

$14.67 \quad 18.28^{(d)}$

$43.42 \quad 133.47^{(1,1)}$

$84.81^{(11)} / 193.20^{(b)} \quad 54.26^{(1)}$

$10.85^{(h)} \quad 4.12^{(1)}$

8.5.24.1 $1^{(h)} \quad 9.0 .11 .8^{(r)}$

.. 0.62

$1.20(1.33) \quad$..

(a) Forward-bias values.

(h) Rack-bias values.

(1.) Mean steady-stare values.

(d) Includes EF trim coil 
TABLE III. TF- AND DF.COIL DESIGN PARAMETERS FOR THE FTF RFP

\begin{tabular}{|c|c|c|c|}
\hline \multirow[t]{3}{*}{ Parameter } & \multicolumn{3}{|c|}{ Volue } \\
\hline & \multirow[t]{2}{*}{ TF Coils } & \multicolumn{2}{|c|}{ DF Coils } \\
\hline & & Nulling & Flanking \\
\hline Number of TF coils & 28 & 4 & 8 \\
\hline Major iadius (m) & 1.80 & 1.86 & 1.85 \\
\hline Minor radius ( $n$ ) & 0.70 & 0.54 & 0.53 \\
\hline Radial thickness $(\mathrm{mm})$ & 1381 & 43.8 & 62.0 \\
\hline Toroidal thickness $(\mathrm{mm})$ & 132.0 & 43.8 & 62.0 \\
\hline Current per coil (kA) & 167.8 & 384.0 & 192.0 \\
\hline C.urrent density $\left(\mathrm{MA} / \mathrm{m}^{2}\right)$ & 9.2 & 200. & 50 \\
\hline Total ohmic power (MW) & $8.8^{(1+1)}$ & $29.9^{(h)}$ & $5.9^{(11)}$ \\
\hline
\end{tabular}

(1) Aluminum coils are used to reduce neutron activation

(h) Copper coils are used to mininize ohmic dissipation 
TABLE IV. COL: ICTOR P!-ATE THERMAL-HYURAULICS PA-

RAMETERS FOR TIHE FTF/RFP

Coolant pipe inner diameter, $d_{I n}(\mathrm{~mm})$ 10.0

Tungsten coating thickness. $\Delta r{ }_{11}(r \cdot m)$

Water coolant velocity, $(m / \mathrm{m})$

2.5

Water inlet temperature, $T_{H, i, 1}^{\prime \prime \prime}\left(C^{\prime}\right)$

Degrees below saturation

temperature, $\Delta T_{s+T}\left(C^{\prime}\right)$

Volumetric heating in metal and water, $\left(Q(A) / I^{3}\right)$

Pipe material

Pipe thickness, $\Delta r(m m)$

Water outlet temperature, 7"ii,', $\left.11^{\prime \prime}\right)$

Water inlet pressure, $1{ }^{\prime i} i_{: 1}, 1.1 / l^{\prime}(1)$

Water pressure drop. $\Delta$

Critical heat flux. $(\text { ' } / 1 / 1.1 / 11 \cdot)^{\prime}$ )

Peak nipe temperature. $T /\left(C^{\prime}\right)$

100.0

Normalized total stress. $\sigma \tau_{y}$

20.0

67.0

Cu SS

$1.0 \quad 0.5$

$110 . \quad 109$.

$0.25 \quad 0.24$

$0.06 \quad 0.06$

$40 \quad 4.0$

$280 \quad 355$

$0.05 \quad 0.34$ 
TABLE V. OFED PARAMETERS FOR THE FTF, RFP

Parameter

Average Plasma Current, $I_{0}(.1 / .1)$

Drive Frequency, $f(H=)$

Torvidal-flux swing. $\delta \phi \phi_{0}$

$\Theta$ Variation

$F$ Variation

Toroidal/Poloidal Circuit ( $/ 111$ )

Plasma Poynting power, $P$

Plasma dissipation. $I_{n}$

First-wall dissipation, I'H

Blanket dissipation. $P_{B}$

Terrininal Qeactive P'ower, $P,(,: I I I)$

$\mathrm{OH}$ coils

TF coils

EF coils

Trim coils

Coil Dissipation, $l, 1,1 / 11)$

$\mathrm{OH}$ coils

TF coils

EF coils

Trim coils

Real (lost) Terminal "Oower. $P^{\prime \prime}, 1 / 11$,

$\mathrm{OH}$ coils

$7 \mathrm{~F}$ coils

EF coils

Trim coils

TF coil de power. I'i, I/II,

EF-coil de power. "ii $1.1 / 11$ ।

Power-supply dissipation. $11,1.11 / 11,1.1$

Total dissipation. I',1.1/1I I

Current-drive power, $1,1,1,1 / 111$

Current dive efficiency, $l_{1}, I, 1,1,11,1,1$
Value

10.20

60

0.035

$1.466-1.581$

$.0 .043-.0 .196$

$2.82675 \quad 114.88$

23.280 .0

0.00000

1.561768

326

944.28

67.19

817.60

0.00

10.64

5463

26.28

006

4415

5261

37.27

882

5261

1832

15241

90.98

0.11

(11) Assumes the power supplies nre $99^{\circ}$, efficient.

(b) This efliciency is based on total power consumes! in the system. An equivalent satimate for $1, f$ cuntent dive in tokamaks is $11.116 \mathrm{i}, 111$ assummng a conversion efliciency of 03 